\title{
Integrating Cloud with Self Service Kiosk: An Impact Study on Society Evolution
}

\author{
https://doi.org/10.3991/ijim.v15i23.27709 \\ Fetoon Algarawi, Nabeel Khan ${ }^{(\varpi)}$ \\ Qassim University, Buraydah, Saudi Arabia \\ n. khanequ.edu.sa
}

\begin{abstract}
Self-Service Kiosks is the invention of moving technologies with improving the services into a new era of rapid development to society. Using Self-Service Kiosks changing the lifestyle schedule of the day, no need to make free time during the working hours to accomplish the services you need, as it's available 24/7. Public sectors are adopting SSKs at a high rate knowing its potential in revolutionizing how services are offered by improving work efficiency, work experience, relieving human workloads and reducing service cost. The integration of cloud technologies with SSK is an emerging tendency. The survey conducted in the form of questionnaire indicates that cloud enabled SSKs are aesthetically appealing and its implementation would assist in offering right content to a right person at the right time. As several industries adopted SSKs technology to provide their services, this study aims to understand the impact of the self-service kiosk on society and explain the association between self-service kiosk and cloud-computing.
\end{abstract}

Keywords - self-service kiosk (SSK), cloud computing, self-service technologies (SST), socio-technological issues

\section{$1 \quad$ Introduction}

Imagining that you have an important physical mail you need to send after working hours of the post office or you have to reissue your ATM card after the bank is already closed, with Self-Service Kiosks (SSKs) you don't need to worry about it. As self-service kiosks allow us to get the services we need 24/7 without interaction with humans [1]. Self-service kiosks (SSKs) are considered as one of the several technological forms of self-service technologies (SST). As SSTs become an important part of our lives, it's widespread across several businesses. Many Studies of (SST) depends on the customer acceptance of the self-service technology [2]. Due to the benefit for both the customers and businesses, as SST reduced the cost of labor, customers get served fast and easy and the benefit behind the availability at any time is to increase the business sales to improvise customer satisfaction [3] [4].

Like many other technologies, SSKs need software to run the system and to store the information. The researcher in [5] and [6] use Cloud computing as one of the effective 
techniques to store and retrieve the data. This research aims to evaluate the impact of cloud-based self-service kiosks on society. This paper is organized as follows: A literature review of Integrating cloud with self-service kiosk is shown in section 2. Section 3 defines the methodology of the research conducted while objectives, problem statement and results are mentioned in section 4 . Section 5 concludes the paper.

\section{$2 \quad$ Literature review}

Because of the rapid development in technology, the interaction between the consumer and technologies is highly increased with no involvement of the service employee, and this is what SSTs refer to [1] [3]. According to [1], the benefits of SSTs as a consumer is "saved time and money, increased accessibility, a variety of choices, convenience, reduced wait times, high levels of personalization, and fast service processing". On the other hand, the benefits as a business are "reduce their financial costs by reducing the number of service employees and increase consumer satisfaction by employing a standardized service delivery and matching customer expectations".

Nowadays, many businesses depend on self-service kiosks as one of the main and important channels of their services. The popular industries that adopted the SSKs [1] [2].
a) Banks
b) Airlines
c) Restaurants
d) Parking ticket
e) Government services
f) Hotels

And the industries are continually growing [4] [7]. To take the banks as an example, SSKs in the bank provide a variety of services, as it's the fastest way to banking services, these services divided into:

a) Card services: Card Issuance.

b) Document Services: Statement printing, IBAN printing, Balance Certificate printing.

c) Other Services: Update Mobile number [8].

Self-service kiosks also work as an alternative assistant in the health fields to reduce the waiting time of the patients and improving the health services [9].

The previous SSKs need a cloud server to run Conveniently [5]. Figure 1, (provided by Advantech Co., Ltd.) shows that the self-service technologies are connected to the self-service server via a secure network to preforms the services for the customers. 


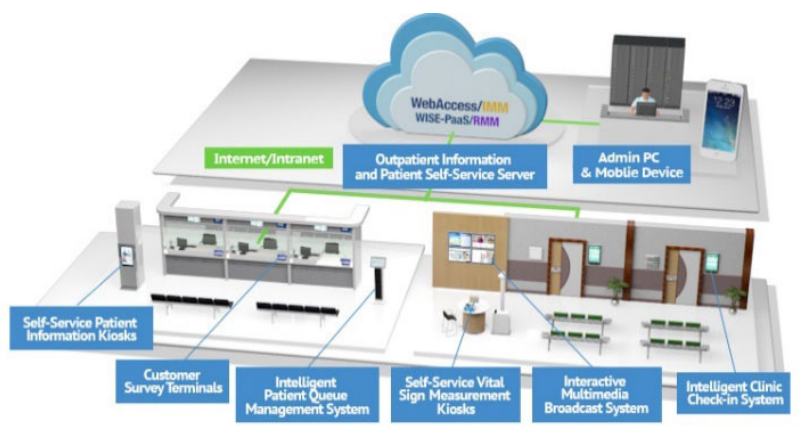

Fig. 1. Self service system

According to [10], the main components of the self-service system that consist of "Transmission Control Protocol (TCP) server, (HMI), MYSQL database, and anomaly detection" as shown in the relationship in Figure 2.

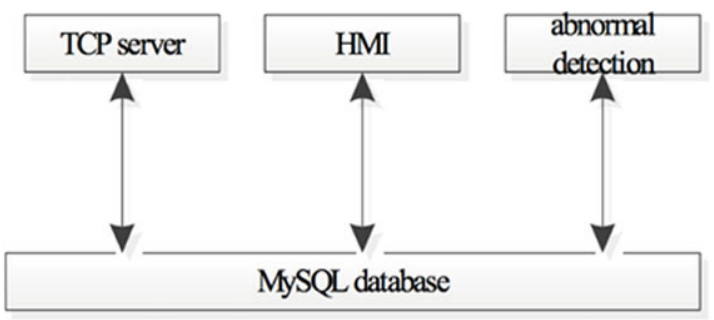

Fig. 2. The relationship between self-service system components

Self-service technologies may lead to success whenever the service providers meet the specification of the customers and give a good visualization of the customers' vision. On the other hand, SSTs may lead to failure whenever the service is provided with weak studies of the customers' needs [11].

Customers evaluate the SSKs using experience depends on a variety of factors and concepts, as the researchers on [12] epitomize "the user experience is related to a variety of concepts, including functional, emotional, affective, experiential, hedonic, and aesthetic" this evaluate experience guided by some elements such as the system that run the SSK, the interface and the services that the customer will giant [13] [14] [15].

Cloud computing is an idea of combining technological resources online. This term first introduced by Google in 2006 and has become the standard in the modern days computing environment. The online resources (Networks, servers, storage, and applications. etc.) can put in a shared pool where any individual or a company can pay-per-use the series of services according to their specific needs with minimal 
management efforts [15] [16] [17]. Cloud leverages many elements inclusive of scale, cost-efficiency, resilience, service orientation, agility, etc. This pay-per-use feature of cloud models enables the user to access the resources as per their requirement from the shared-pool online resources available on the network. The end-user can access resources 24/7 from anywhere using various types of devices such as laptops, desktop, and smartphone. The platforms (System Software) and infrastructure (Hardware) use to execute different application software that user access and use online on-demand as follows in Figure 1 [1] [2].

A study conducted in 2019, states the association of Cloud technology with SSK. A working system is presented in order to create a new system for users improving overall efficiency and effectiveness. This proposed architecture (as mentioned in Figure 3) is implemented in Self Service health monitoring and management KIOSK, providing solution to keep a track of vital medical parameters such as blood pressure, body fat, body mass index (BMI) etc. [18] [19].

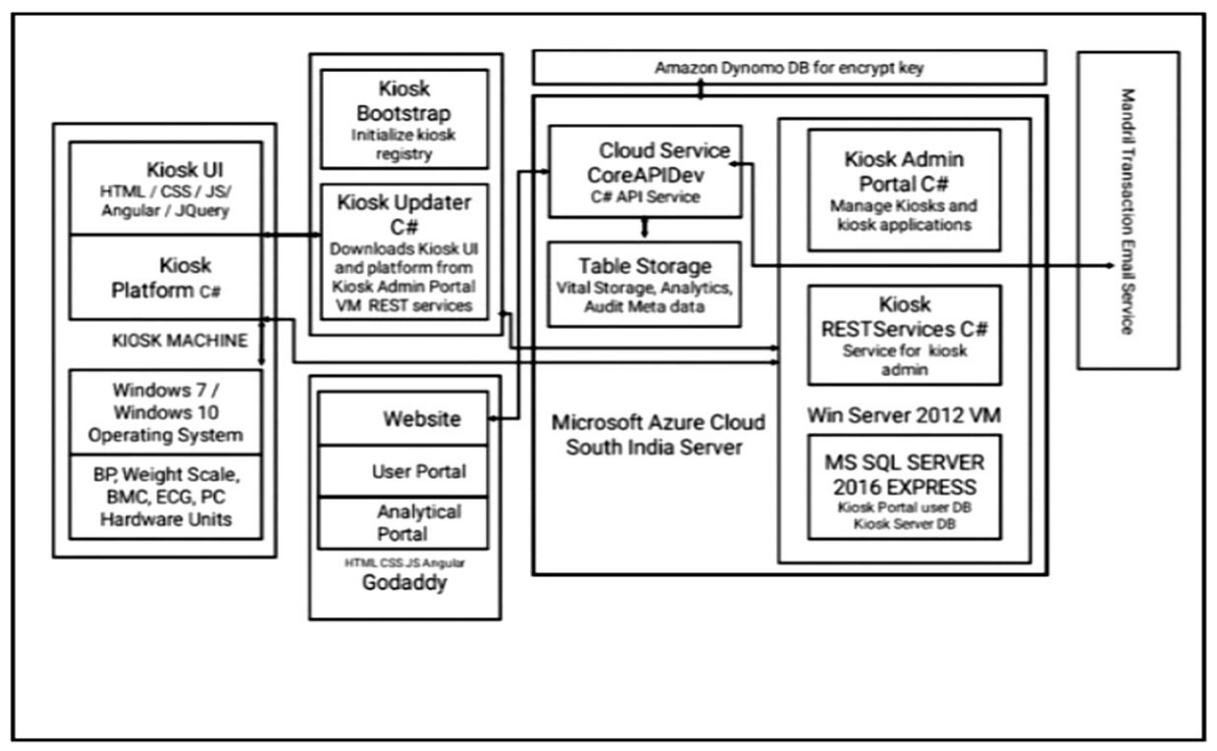

Fig. 3. The integrated self service kiosk explaining association of cloud technology with SSK

\section{Research methodology}

The data was collected through an online survey questionnaire. To build the survey in this research we used (Google. form) (Table 1). The questionnaire was based on society's knowledge of the self-service kiosks; it was divided into two main parts of questions (Table 3). Thus the final questionnaire was used to collect data from 300 
respondents (Table 2). The survey was passed on to different ages. The parts of the survey were divided into an introduction and main part questions. The introduction is about knowing the knowledge of SSKs in society and asking about the age of the responder:

Table 1. Questionnaire 1

\begin{tabular}{|l|c|c|}
\hline \multicolumn{1}{|c|}{ Category } & Frequency & Percentage (\%) \\
\hline Do you know what is Self-Service Kiosk? & 273 & $91 \%$ \\
\hline Yes & 3 & $1 \%$ \\
\hline No & 24 & $8 \%$ \\
\hline Maybe & \multicolumn{2}{|c|}{} \\
\hline Age & 63 & $21 \%$ \\
\hline $15-25$ & 64 & $21.3 \%$ \\
\hline $26-30$ & 33 & $11 \%$ \\
\hline $31-40$ & 68 & $22.7 \%$ \\
\hline $41-50$ & 72 & $24 \%$ \\
\hline $51-60$ & & \\
\hline
\end{tabular}

The main part questions were a (yes or no) questions and (multiple choice) questions.

Table 2. Questionnaire 2

\begin{tabular}{|l|c|c|}
\multicolumn{1}{|c|}{ Yes or No questions } & \multicolumn{2}{c|}{ Frequency } \\
\cline { 2 - 3 } & Yes & No \\
\hline $\begin{array}{l}\text { Do you think that using SSKs making the accomplishment of } \\
\text { personal tasks faster? }\end{array}$ & 286 & 14 \\
\hline Do you support having SSKs in all possible places? & 277 & 23 \\
\hline $\begin{array}{l}\text { When you enter the service provider that provides SSKs do you } \\
\text { prefer to use the kiosk instead of dealing with an employee directly? }\end{array}$ & 210 & 90 \\
\hline SSKs contribute to the evolution of society? & 278 & 22 \\
\hline SSKs have many problems and do not work as required? & 91 & 209 \\
\hline Do you think the SSKs are secure to use? & 252 & 48 \\
\hline $\begin{array}{l}\text { Did you know that some SSKs depend on cloud computing to } \\
\text { identify and retrieve data? }\end{array}$ & 165 & 135 \\
\hline
\end{tabular}


Table 3. Questionnaire 3

\begin{tabular}{|l|c|c|}
\hline \multicolumn{2}{|c|}{ Multiple Choice Questions } \\
\hline $\begin{array}{l}\text { Q1: Choose one or more problems you faced } \\
\text { when you use SSKs: }\end{array}$ & Frequency & Percentage (\%) \\
\hline I have not faced any problems worth to mention & 132 & $44 \%$ \\
\hline Personal data has been stolen & 5 & $1.7 \%$ \\
\hline The kiosk stops working while using it & 63 & $21 \%$ \\
\hline Repeat the steps & 101 & $33.7 \%$ \\
\hline Failure to recognize in case of a fingerprint request & 46 & $15.3 \%$ \\
\hline Taking more time than required to implement the service & 83 & $27.7 \%$ \\
\hline Q2: Choose one or more services in which you use SSK & Frequency & Percentage (\%) \\
\hline Print the ATM card and other banking services & 217 & $72.3 \%$ \\
\hline Restaurants & 177 & $59 \%$ \\
\hline Ministry of Interior (e.g.Absher In Saudi Arabia) & 225 & $75 \%$ \\
\hline Telecom companies & 118 & $39.3 \%$ \\
\hline Airports and airlines & 127 & $42.3 \%$ \\
\hline Government units facilities & 104 & $34.7 \%$ \\
\hline Shopping Center (Mall) & 154 & $51.3 \%$ \\
\hline
\end{tabular}

\section{$4 \quad$ Results and discussion}

\subsection{Objectives}

a) To evaluate the knowledge of the SSK on the society.

b) To study the impact of the SSKs.

c) Test the knowledge of the relationship between cloud-based and SSKs.

d) Evaluate the problems with SSKs usage.

e) Challenges of Cloud Computing in Education

\subsection{Problem statement}

Organizations and governments units rely on self-service kiosks extremely and rapidly, which requires understanding the extent of acceptance and impact of self-service kiosks on society, to know the possibility of spreading SSKs properly.

\subsection{Results and recommendations}

About $91 \%$ of responder they already know SSK, in the other hands 3 people out of 300 doesn't know what Self-Service Kiosk, this reflects the publicity of SSK on the society.

Using (yes or no) questions to evaluate the usability of SSK, the result shows that more than $75 \%$ of the responder agrees that SSK is more useable and effective 
these days. 210 out of 300 they prefer to use SSK rather than dealing directly with the employees, this point of view from the responder side is because they think that SSK is trustworthy.

The relationship between Cloud Computing and SSK is not very popular, as the study shows that 165 out of 300 responders know that using Cloud Computing to retrieve data. Based on the responders' answers, most of the problems they face when using SSK is that force them to repeat the step, which will make them take more time than expected. In general, all the fields that provide self-service kiosks are more useable for society as they prefer to use SSKs

This study shows how important the implementation of SSKs from services providers, the survey that fulfills in this study shows how much society has a high acceptance of using self-service kiosks. Now the pressure will be on the services providers to study the need of their customers to provide a SSK to meet the customers' expectations. In this case, the services providers need to work step by step to succeed, the recommendation on this study depends on the background of the society's knowledge of self-service technologies, based on that by using SSKs services providers have the empower to increase their profit by providing the services all the time, improve their services by giving the customers the chance to choose how they want to be served and raise customer's loyalty by gaining their trust.

\section{Conclusion}

Nowadays, technology solutions solve many problems, as it works as a primary channel to provide services to customers, the primary goal is to facilitate the implementation of the services to improve society. Self-service kiosks provide an easy way for accomplishing the main services that can be completed from the system by the customer itself. The information is Connecting from the services providers' database into the kiosk to the user, usually via cloud computing. SSKs is an easy and secure way, furthermore, it has a high protection system to prevent fraud as it works with sensitive and private information.

\section{References}

[1] Yoon, C., and Choi, B. (2020). Role of situational dependence in the use of self-service technology. Sustainability, 12(11), 4653. https://doi.org/10.3390/su12114653

[2] Wang, C. (2017). Consumer acceptance of self-service technologies: An ability-willingness model. International Journal of Market Research, 59(6), 787-802. https://doi.org/10.2501/ IJMR-2017-048

[3] Baranovski, I., Stankovski, S., Ostojić, G., Horvat, S., and Srdjan, T. (2020). Augmented reality support for self-service automated systems. Journal of Graphic Engineering and Design, 11(1), 63. https://doi.org/10.24867/JGED-2020-1-063

[4] Vakulenko, Y., Oghazi, P., and Hellström, D. (2019). Innovative framework for self-service kiosks: Integrating customer value knowledge. Journal of Innovation and Knowledge, 4(4), 262-268. https://doi.org/10.1016/j.jik.2019.06.001 
[5] Baranovski, I., Stankovski, S., Ostojić, G., and Horvat, S. (2020, March). Support for Selfservice Automated Parking Systems. In 2020 19th International Symposium InfotehJahorina (Infoteh) (pp. 1-5). IEEE. https://doi.org/10.1109/INFOTEH48170.2020.9066319

[6] Kumar, N. K., Bhavani, R., Mohan, A., and Vigneswari, D. (2019). ISSK-an integrated self service kiosk for health monitoring and management. International Journal of Scientific and Technology, 8(9), 2388-2393.

[7] Hong, C., and Slevitch, L. (2018). Determinants of customer satisfaction and willingness to use self-service kiosks in the hotel industry. Journal of Tourism and Hospitality, 7(5), 1-7. https://doi.org/10.4172/2167-0269.1000379

[8] https://www.alahli.com/en-us/personal-banking/banking-and-e-services/Pages/ Self-Service.aspx (Accessed on: 20th June, 2021).

[9] Pacheco, P., Santos, F., Coimbra, J., Oliveira, E., and Rodrigues, N. F. (2020, August). Designing Effective User Interface Experiences for a Self-Service Kiosk to Reduce Emergency Department Crowding. 8th International Conference on Serious Games and Applications for Health (SeGAH), IEEE, Canada, 2020, pp. 1-8. https://doi.org/10.1109/ SeGAH49190.2020.9201858

[10] Lin, Q., Wei, L., Yonggui, G., and Zhonghai, L. (2020, April). Research on Test of Terminal Safety Performance in Power Self-service Application System. In 2020 International Conference on Urban Engineering and Management Science (ICUEMS), IEEE, 2020, pp. 661-665. https://doi.org/10.1109/ICUEMS50872.2020.00145

[11] Meuter, M. L., Ostrom, A. L., Roundtree, R. I., and Bitner, M. J. (2000). Self-service technologies: Understanding customer satisfaction with technology-based service encounters. Journal of Marketing, 64(3), 50-64. https://doi.org/10.1509/jmkg.64.3.50.18024

[12] Chen, T., Guo, W., Gao, X., and Liang, Z. (2020). AI-based self-service technology in public service delivery: User experience and influencing factors. Government Information Quarterly, 101520. https://doi.org/10.1016/j.giq.2020.101520

[13] Park, S., Lehto, X., and Lehto, M. (2021). Self-service technology kiosk design for restaurants: An QFD application. International Journal of Hospitality Management, 92, 102757. https://doi.org/10.1016/j.ijhm.2020.102757

[14] Halim, S. A., Othman, M. H., Buja, A. G., Rahid, N. N. A., Sharip, A. A., and Zain, S. M. M. (2021). C19-SmartQ: Applying real-time multi-organization queuing management system using predictive model to maintain social distancing. International Journal of Interactive Mobile Technologies (iJIM), 15(6), 108-123. https://doi.org/10.3991/ijim.v15i06.20597

[15] Junaid, M., Shaikh, A., Hassan, M. U., Alghamdi, A., Rajab, K., Reshan, A., and Alkinani, M. (2021). Smart agriculture cloud using AI based techniques. Energies, 14(16), 5129. https:// doi.org/10.3390/en14165129

[16] Tamani, S., Amad, Z., Abouhanifa, S., El-Khouzai, E., and Radid, M. (2021). Analysis on the actions of a continuous distance training session for teachers and its impact on their actual practices. International Journal of Interactive Mobile Technologies (iJIM), 15(17), 119-140. https://doi.org/10.3991/ijim.v15i17.22411

[17] Naveed, Q. N., Qureshi, M. R. N., Tairan, N., Mohammad, A., Shaikh, A., Alsayed, A. O., and Alotaibi, F. M. (2020). Evaluating critical success factors in implementing E-learning system using multi-criteria decision-making. Plos One, 15(5), e0231465. https://doi. org/10.1371/journal.pone.0231465

[18] Ghani, M. S. A., Abidin, N. Z., Abd Rahman, R., Wibowo, A., and Alwi, A. (2021). Modelling the impact of mobile application adoption on the taxi demand: An application of a system dynamics approach. International Journal of Interactive Mobile Technologies (iJIM), 15(6), 18-31. https://doi.org/10.3991/ijim.v15i06.20633 
[19] Shaikh, A., Uddin, M., Elmagzoub, M. A., \& Alghamdi, A. (2020). PEMC: Power Efficiency Measurement Calculator to Compute Power Efficiency and CO-Emissions in Cloud Data Centers. IEEE Access, 8, 195216-195228. https://doi.org/10.1109/ACCESS.2020.3033791

\section{$7 \quad$ Authors}

Fetoon Khaled M Algarawi is a student of Department of Information Technology, College of Computer, Qassim University, Buraydah, Saudi Arabia (email: 421200022@, qu.edu.sa).

Dr Nabeel Khan is an Indian Assistant Professor at Department of Information Technology, College of Computer, Qassim University, Buraydah, Saudi Arabia (email: n.khan@qu.edu.sa).

Article submitted 2021-09-07. Resubmitted 2021-10-20. Final acceptance 2021-10-21. Final version published as submitted by the authors. 